\title{
Dermatitis due to Alkalis
}

National Cancer Institute

\section{Source}

National Cancer Institute. Dermatitis due to Alkalis. NCI Thesaurus. Code C35310.

Contact dermatitis caused by exposure to alkalis. 